\title{
LA DONCELLA DE HIERRO Y LA ODALISCA: METAFISICA DE UNA IMAGEN FEMENINA
}

CARMEN GONZÁLEZ MARÍN*

Universidad Carlos III de Madrid

"Así como vemos que las mujeres producen ellas solas amasijos y trozos de carne informes, y que, para que engendren algo bueno y natural, se las ha de preñar con otra semilla, así ocurre con el pensamiento.»

(Michel de Montaigne: Sobre la ociosidad)

Uno de los fenómenos que debería resultar sorprendente en éste nuestro siglo de las mujeres es la cara ambigua de las imágenes de la mujer y la ambivalencia en la interpretación de los comportamientos femeninos a que asistimos cotidianamente. La liberación sexual, acompañada de la autonomía económica, así como el control del propio cuerpo y de la propia imagen de los eslóganes del feminismo más radical auguraban un futuro que se asemeja poco a algunas parcelas notoriamente visibles de nuestro presente. La aparente relevancia moral y económica que adquiere la exhibición del cuerpo y la vida sexual de ciertas mujeres se compadece mal con la asumida liberación y autocontrol, y, en definitiva, parece presentarse como un caso de regresión a modos de interpretar -autointerpretarse- a las mujeres bajo fórmulas semejantes a las que utilizaban Mary Wollstoncraft o John Stuart Mill cuando denunciaban las formas de vida femeninas generadas por un contrato sexual que se basaba en el intercambio de «sexo por pan».

La pregunta más inocente que uno podría plantearse no es otra que ésta: si liberarse de las formas de exclusión y subordinación suponía para las mujeres

\footnotetext{
*Este ensayo, junto con los trabajos inéditos "Dos dogmas del feminismo" y "Genealogía del mal», forma la base de una investigación más amplia. El carácter esbozado de algunos de los puntos en este texto se debe, por ello, al estatuto embrionario de la misma. La reflexión acerca de estas cuestiones se ha visto sin duda enriquecida por todas aquellas personas que han participado, como alumnos o como docentes, en los diferentes cursos que se me ha dado la oportunidad de impartir en torno a cuestiones relacionadas con el feminismo, tanto en el marco de los Cursos de Humanidades como en el Programa de Doctorado de la Universidad Carlos III. Deseo por ello agradecer a sus responsables su estimulante empeño en la promoción y mantenimiento de este tipo de cursos.
} 
adquirir una mayoría de edad, que debiera manifestarse en un autocontrol y en una autonomía que las hiciera independientes de todo contrato sexual, y suponía, al mismo tiempo, devolverles una imagen propia y no ya la imagen especular del objeto sexual del varón, ¿ha fracasado el empeño del feminismo?, ¿quizá ha fracasado sólo localmente, en un cierto sector de mujeres? Si el feminismo no ha fracasado y la conciencia pública ha sido efectivamente transformada por sus revoluciones en todos los ámbitos, ¿por qué la imagen femenina-slim and sexy, decía Rosalind Coward ${ }^{1}$, a lo que añadiría públicamente reconocida y convertida en moneda de cambio- no responde a tal transformación, precisamente en sus aspectos más visibles?

A partir del conocido tratamiento de Lipovetsky² podríamos simplemente asumir que a las mujeres les ha acontecido algo que las coloca en una situación peculiar, dado que han desaparecido ciertos estereotipos tradicionales, pero todavía perviven otros, o una parte de ellos. Quizá asistimos a un ocultamiento explícito de los estereotipos tradicionales en pro de una política de corrección, pero, a la vez, a una sumergida pervivencia de los mismos. Esta descripción no parece errónea en ciertos sectores de la vida de las mujeres, pero, aunque podría ayudar a explicar las ambigüedades del tratamiento de las imágenes femeninas y de sus interpretaciones, no nos basta para entender la paradójica relevancia que una determinada forma de presentación ha adquirido para las mujeres; relevancia, que, creo, excede con mucho las patologías o los excesos de ciertos medios de comunicación, porque halla su fundamento en su propio carácter normativo.

Obviamente podríamos tratar de dar con una respuesta ad hoc, pero es posible tratar de hacer explícito un proceso de mayor calado e interés que, sospecho, no es nuevo, ni obedece a los imperativos de la era mediática, sino que más bien reproduce el más tradicional de los mecanismos de control sobre las mujeres, con todas las ambigüedades que ello conlleva. Esta denuncia, sin embargo, no es todo lo que podríamos concluir de un análisis pormenorizado de las ambigüedades en la presentación de las imágenes femeninas y en sus interpretaciones. En realidad, nos encontramos ante el planteamiento de un problema que no afecta sólo a las mujeres y cuyas vías de solución habrán de ser transitadas esta vez por mujeres y varones, porque lo que está en entredicho es la pervivencia y la validez de nuestra idea de sujeto.

\section{FILOSOFÍA Y MATERIA FEMENINA}

A la filosofía le atraen las dicotomías, como es sabido. Una de éstas, o la más sustancial, es precisamente materia versus forma. No resulta novedoso estructurar todo un sistema de oposiciones bajo esta primera y capital, de modo que den cuenta bastante cabalmente de una estructura conceptual que localiza a las mujeres rígidamente en el espacio demarcado por uno de los miembros de

1. Véase Coward, Rosalind: Our Treacherous Hearts Why Women Let Men Get Their Way, London, Faber and Faber, 1992.

2. Véase Lipovetsky, Gilles: La tercera mujer, Barcelona, Anagrama, 1999. 
tales oposiciones: materia, cuerpo, instinto, naturaleza, pasividad, apariencia, etc, frente a forma, alma, razón, cultura, acción, realidad etc.

Naturalmente, no es mi intención analizar ni mucho menos explicar las razones de índole antropológica o psicológica que han determinado a nuestra tradición a decantarse por esa interpretación y no otra. Pero sí deseo llamar la atención acerca de algunas de las maneras en que esas dicotomías y específicamente la primera de ellas han actuado, y siguen haciéndolo, en nuestros modos de conceptualizar a las mujeres.

A grandes rasgos, las ambigüedades de que daba cuenta más arriba son la consecuencia de la pervivencia de la arcana dicotomía materia / forma. Dicho en otros términos, mi sospecha es que, como siempre, las mujeres siguen siendo pasto de una abstracción platonizante y desnaturalizadora que, si bien no es exclusiva de este ámbito como proceso, las convierte en opacas representantes de una «idea». Este lugar común merece algún intento de explicación. Mi propósito es, partiendo de tal lugar, presentar tres ejemplos que ayudan a visualizar y tal vez hacer plausible una hipótesis: si las mujeres han sido interpretadas y lo siguen siendo bajo el espectro de una metafísica platonizante es precisamente porque tenemos dificultades para tolerar la contingencia, el cambio y posiblemente la muerte.

\section{LA DONCELLA DE HIERRO O DE LO INMUTABLE}

De la estética feminista hemos aprendido cómo se articula en el mundo del arte, y por supuesto en el propio mundo de la estética filosófica, la oposición materia / forma. La necesidad de instituir un modo de presentación y representación del cuerpo femenino en el arte delatan el carácter normativo de la formalización de la materia femenina $-y$, por ello, la importancia de instruir adecuadamente desde los tratados de arte y desde las escuelas o academias igualmente. Este carácter normativo es precisamente lo que delimita la aceptabilidad de un desnudo artístico frente a la pornografía, como argumenta Lynda $\mathrm{Nead}^{3}$.

Hay dos puntos que merecen ser destacados en esta rápida aproximación: por una parte, el hecho de que el Desnudo con mayúsculas, el caso del desnudo por antonomasia, sea el desnudo femenino tiene una significación relevante para mi argumento. Dar forma, hacer aceptable, inteligible, visible, etc. un cuerpo femenino es la prueba más dura, y ésta es la razón por la que el desnudo femenino es la culminación y el paradigma del Arte, también con mayúsculas. Por otra parte, el hecho de que un cuerpo debidamente formalizado es aceptable estética y también moralmente, frente al carácter culpable de la pornografía parece explicarse, de nuevo siguiendo a Lynda Nead, en términos de la recepción por parte del espectador. El espectador de un Desnudo artístico idealmente reacciona a la kantiana, es decir, afronta la situación de modo estático, según las pautas del modo de percepción desinteresada. Por el contrario, el espectador de

3. NEAD, Linda: El desnudo femenino, Madrid, Tecnos, 1992. 
un desnudo pornográfico se caracteriza por un modo de percepción en la que prima lo dinámico y en la que hay una obvia implicación de la sensualidad. Por supuesto, la diferencia entre la percepción de uno y otro viene determinada por el objeto mismo. Es por tanto fácil concluir que la presencia de la forma artística nos coloca en el estado deseable para una percepción de la belleza -acaso habría de ser escrita en mayúsculas- mientras que la ausencia de esa forma nos deja abandonados en el territorio dominado por los sentidos, donde no es «La Belleza» sino el cuerpo, concreto y susceptible de ser aprehendido sensorial y no intelectualmente, lo que se nos da. No es preciso ir más allá para apreciar la armadura platónica que se hace explícita en tal modo de ver el arte, y específicamente el desnudo femenino como su caso paradigmático.

Lejos de manifestarse como un modo arcaizante, obsoleto tras la crítica feminista, esta fórmula estético-normativa que afecta a la representación y a la percepción del cuerpo femenino parece algo totalmente vigente. Los rituales de la belleza femenina, desde el bodybuilding hasta las prácticas quirúrgicas manifiestan la misma tendencia con una peculiaridad: esta vez no es alguien ajeno a las mujeres quien impone un patrón metafísicomoral, sino que las mujeres han asumido su papel de agentes de su propia auto-formalización.

Ésta es una de las paradojas que chocan más vivamente en nuestros tiempos sin duda. Y la sospecha, ya hecha explícita por parte de ciertas feministas, de una violencia no gratuita, sino instrumentalizada para lograr pingües beneficios económicos, no puede dejar de tomarse en consideración. Quizá la respuesta de la agresión mistificadora no acabe de satisfacer, no obstante, porque deja en muy mal lugar a las propias mujeres. Eso nos permite plantear como plausible otro intento de explicación. Tal explicación tendería a presentarse como una tesis radical: la mujer no es asimilada/able como un ser con todas sus contingencias, sino que ha de imponérsele siempre una estructura que la define como femenina en un sentido ideal y adecuado por tanto.

Recordemos solamente el comienzo del libro V de Emilio. Rousseau, el gran mistificador de la domesticidad, plasma en las primeras líneas de su tratado acerca de la mujer y sus relaciones con el varón, el carácter eminentemente normativo de la feminidad: "así como Emilio es hombre, Sofía debe ser mujer». Desde luego no es el único ejemplo de que podríamos echar mano. Pensadores genuinamente favorables a la liberación de las mujeres como John Stuart Mill o Mary Wollstoncraft parecen de nuevo asumir formas de idealización normativa que en este caso determinen un modelo de mujer distinto del que promueve una "educación falsa» o un contrato sexual desigual y subordinador para las mujeres.

En El mito de la Belleza, Naomi Wolf utilizaba como alegoría del grado de coacción y violencia a que se ven sometidas las mujeres, en la que denominaba la "era quirúrgica», la figura de la "doncella de hierro» ${ }^{4}$. La doncella de hierro denominaba a una máquina de tortura, un artefacto antropomórfico en el que

4. Wblf, Naomi: El mito de la Belleza, Barcelona, Salamandra, 1992. 
se introducía a la víctima que había de ser torturada. La figura de "la doncella de hierro» es una buena alegoría de los procedimientos con que se formaliza el cuerpo de las mujeres sometidas a las mistificaciones de una idea de belleza, entendida como piedra angular de una religión cruenta, tal como la define Wolf. Pero ilustra también la representación platónica de un imagen femenina que, obviamente, como toda Idea, no corresponde con lo sensible, sino que pretende presentarse como jerárquicamente superior desde todos los puntos de vista.

Wolf pretendió con su denuncia poner en entredicho el carácter liberador del control sobre el cuerpo que representan las formas contemporáneas de autointerpretarse como un ser plástico. Pero a ello habría que añadir que tal "plasticidad» excede con mucho las fronteras de lo que podríamos denominar cultural, para alcanzar una dimensión metafísica. Se trata de dar con procedimientos de control sobre el tiempo o sobre la contingencia. En otras palabras, es bien explícita la paradoja que constituye nuestro punto de partida en esta reflexión. Si el feminismo había acusado a la tradición estética, y más modernamente a los dictados de la dietética y la moda, de una dosis de violencia patriarcal que imponía una imagen corporal supeditada a los intereses y las exigencias de un sujeto masculino, la curiosa consecuencia del alborozo con que se acogen los necesarios medios de intervención para construirse una imagen aceptable es la paradoja de la víctima aquejada de síndrome de Estocolmo. Y ello no como una consecuencia del control social que se ejerce merced a los modos culturales y por ello supeditadas a cambios, sino precisamente por razones metafísicas.

\section{LA ESPOSA INOCENTE O DE LA CERTEZA}

Entre los escritores del barroco español, María de Zayas y Sotomayor se singulariza por su vertiente apologética para con las mujeres. Sus Desengaños y su $\mathrm{Sarao}^{5}$ narran historias centradas en relaciones amorosas y en los descalabros que para los dos sexos conllevan. Si bien podría pensarse que el propósito de los textos de María de Zayas es defender a las mujeres de los peligros que les acechan en sus relaciones con los varones, el grado de ambigüedad en el tratamiento de las situaciones que se retratan en sus historias hace en ocasiones dudar de sus buenas intenciones.

Una de las historias más interesantes, que lleva el significativo título de $E l$ prevenido engañado, nos sirve como ejemplo de otra de las maneras en que lo que podríamos denominar un "control metafísico» afecta a las mujeres en un nivel diferente -si bien no ciertamente desligado del anterior. El prevenido engañado narra la historia de Don Fadrique y sus frustrados intentos por dar con una esposa ideal. Una esposa ideal es por supuesto aquélla que reúna las propiedades físicas y morales que la conviertan en el adorno y la salvaguarda del honor de su marido al mismo tiempo. Pero belleza y castidad no hacen buenas migas en una sola mujer. De modo que Don Fadrique -galán favorecido por los bienes de naturaleza y fortuna- sufre una y otra vez la humillación sentimental de verse

5. Véase Zayas y SOtOmaYor, María de: Novelas amorosas y ejemplares, Madrid, Cátedra 2000 y de la misma autora Desengaños amorosos, Madrid, Cátedra, 1983. 
utilizado por una serie de mujeres, cuya característica común es su deshonestidad en materia sexual. Desengañado de sus interminables desventuras amorosas, que afortunadamente se han producido antes del matrimonio, con lo cual su honra permanece en impecable estado, Don Fadrique decide poner drásticamente fin a la incertidumbre que provoca la baja calidad moral de las mujeres, y se embarca en la etapa definitiva de su vida. Creyendo haber sido todo lo astuto que es necesario para liberarse de las malas artes femeninas, contrae matrimonio con la más inocente de las mujeres.

Al comienzo del relato, habíamos encontrado a Don Fadrique como pretendiente a una dama de nombre Serafina. Pero la dama otorgaba a escondidas sus favores a otro hombre, y, fruto de esas relaciones ocultas, había traído al mundo a una niña, que fue abandonada nada más nacer. La intención de la madre era, superado el momento dificultoso y habiendo sido abandonada por su amante, contraer finalmente matrimonio con su pretendiente Don Fadrique. Pero, para desgracia de Serafina, Don Fadrique había sido testigo de su alumbramiento culpable y, además, había recogido a la criatura que, tiempo después, en edad aún muy temprana, fue ingresada en un convento para que no conociese nada del mundo. Pues bien, este prevenido, que decide poner fin a sus cuitas, cree hacerlo precisamente contrayendo matrimonio con esa criatura inocente.

De ese modo, en realidad, parecería que todos los intentos del caballero por dar con la esposa ideal no eran sino una ficción que estaba destinada a corroborar una tesis previa, la de que no hay mujer casta que pueda guardar la honra de su marido, al menos no la hay "en el mundo». La inocente doña Gracia, nombre en sí mismo también significativo, reúne en cambio todas las virtudes necesarias: es bella y es ignorante de las cosas del amor, por tanto -se infiere ilegítimamente- tendrá un comportamiento predeciblemente honesto. $\mathrm{Su}$ ignorancia hace necesario que el marido la instruya en la "vida de casados», y, de este modo, será él quien "dé forma» a la moralidad de su esposa. Pero el marido comete el error de hipotecar su honra usando como garantía la bobalicona aceptación de una mentira por parte de su esposa. María de Zayas juega magistralmente con los instrumentos propios de la construcción de un vodevil, para hacer del engaño de este "prevenido" un arma que se vuelve, una vez más, contra él. El esposo confiado ha enseñado a la candorosa doña Gracia que la vida de casados consiste, para la mujer, en vestir una armadura y velar el sueño del esposo. No contaba con que el candor y la credulidad podría muy bien aceptar otras vidas de casados más regaladas, como así ocurre. Un caballero, que aprovecha la ausencia del marido, enseña otra «vida de casados» que a la esposa parece más amable, y, a la vuelta de Don Fadrique, es ella misma quien le da cuenta de sus progresos en ese aprendizaje.

Es evidente que la defensa de las mujeres que uno podría presuponer en la historia queda seriamente dañada por la conclusión a la que hemos de llegar. Las mujeres no quedan en buen lugar y la moraleja del cuento es que más vale una mujer discreta y hábil que una boba. Las razones de la moraleja de índole meramente pragmática se resumen en la apreciación de que la discreta al menos sabrá gestionar su infidelidad sin dañar demasiado su imagen. La imagen del 
varón también aparece dotada de todo tipo de rasgos negativos y ambiguos: es él el hacedor de una doble moral que en definitiva acaba por perjudicarle, de modo que es el más vulnerable de los dos, dado que necesita angustiosamente responder por un bien que, siendo su patrimonio, está en manos de otra.

En realidad, si bien se mira, en esta historia Don Fadrique está representando la búsqueda de la certeza. La mujer ideal es la garantía de la certeza. Esa certeza está en el origen de la doble moral, de todas sus versiones probablemente, pero específicamente de aquellas que, como la que detentará Rousseau en Emilio, se configuran como el mecanismo que salvaguarda la transmisión legítima del patrimonio ${ }^{6}$. La mujer es fuente de incertidumbre, de ahí la necesidad de ahormarla también moralmente. La figura de la inocencia que representa Doña Gracia tiene ese estatuto peculiar cognitivo-moral que la hace alegoría de la certeza. No es irrelevante que la imagen que presenta esta esposa-escudo del honor se asemeje a la de una Palas Atenea, una figura que remedia la angustia de la incertidumbre remedando la imagen de un guerrero varonil.

La idealización moral en este caso confiere a doña Gracia el estatuto de aquellos para quienes el mal es imposible. La inocencia, cuyo otro nombre pudiera bien ser pureza, define a la esposa como unívocamente casta, y si es así es simplemente porque la idealización en este caso, como en el caso anterior también, posee un carácter transcendental. Dicho en otras palabras, sólo la mujer convenientemente formalizada es efectivamente una mujer aceptable, la idealización, el ahormamiento de cualquiera de las dos índoles examinadas, es la condición de posibilidad de ser mujer-esposa que es la traducción común de «mujer aceptable».

Si atendemos también al breve análisis desarrollado en el punto primero de este texto, podemos afirmar que algo hay en común entre la formalización del cuerpo y la formalización moral, y que ello es precisamente que tratan de convertir a la mujer en una figura que no posee el estatuto contingente o abierto de lo que puede presentarse bajo una pluralidad de formas o de comportamientos no controlados de antemano.

\section{LA ODALISCA LIBERADA O DE LA IDENTIDAD}

Los ejemplos que venimos exponiendo se articulan en torno a una tesis que podría reescribirse como sigue: "Mujer» es un concepto transcendental cuya necesidad viene impuesta por el estatuto contingente de las mujeres en diferentes

6. Afirma Rousseau que la «ley natural» hace que las mujeres por sí mismas y por sus hijos estén «a merced de los hombres». De ahí se sigue la importancia capital que ha de tener para ellas hacerse querer por los hombres. Es en este contexto en el que hemos de interpretar a continuación la doble moral que se define, como es sabido, al afirmar que en las mujeres son seres especulares, cuya entidad moral depende tanto de su conducta como su reputación. "El hombre cuando obra bien -recuerda Rousseau- sólo depende de sí mismo y puede arrostrar el juicio del público, pero la mujer, cuando obra bien, sólo tiene hecha la mitad de su tarea, y no le importa menos lo que de ella piensen que lo que efectivamente es. De aquí se deduce-concluye- que, a este respecto, el sistema de su educación debe ser contrario al nuestro; la opinión es el sepulcro de la virtud para los hombres, y para las mujeres es su trono.» (Emilio, Libro V) 
niveles, que van de lo físico a lo moral. Creo que las ambigüedades de la imagen femenina cotidiana en nuestros mundos mediáticos de nuevo nos sirven como ejemplos en la misma línea. El caballo de batalla del feminismo ha sido la lucha por la identidad de las mujeres. La lucha por la autoconstrucción de una identidad presenta múltiples facetas, pero hay una de ellas que me gustaría resaltar, porque incide de lleno en la cuestión que aquí nos ocupa.

Recordemos por un instante el título del más célebre libro de salud femenina del siglo XX, Our Bodies Ourselves ${ }^{7}$. El libro, al que se ha llamado «la biblia de la salud femenina», pero también no asignificativamente su mismo título, resultó revolucionario en su día, y sigue constituyendo un punto de referencia importantísimo en lo que concierne a los modos de interpretar lo femenino. Pensemos solamente en el título por el momento. Sin lugar a dudas, admite una lectura inmediata, directa, normativa que se traduce en un enunciado del tipo «nuestros cuerpos han de ser de nuestra propiedad». Pero también permite una segunda lectura - «nosotras somos nuestros cuerpos»- que perversamente reinscribe, en el mismo intento de recuperar el control, y con él la identidad, los peores prejuicios de la tradición misógina. Así, la fuerza de este título-eslogan resulta liberadora en su carácter normativo, pero perversamente cargada del más añejo regusto misógino en su carácter descriptivo. Sabemos, no obstante, que la diferenciación normativo/descriptivo es demasiado borrosa, que lo factual y lo normativo se hallan demasiado "enmarañados» ${ }^{8}$, como para no percibir la facilidad con que podemos resbalar del optimismo normativo a la regresiva y recalcitrante descripción de la mujer en términos sólo comparables al viejo dictum "tota mulier in utero».

Creo que la interrogación acerca de las ambigüedades y del alcance real de la lucha feminista con que se abría este ensayo tiene parte de su origen al menos en este equívoco. Porque la liberación sexual y la manera en que ésta se liga a la construcción de una identidad femenina, una identidad como sujeto y no como objeto, parecen tejerse sobre ese equívoco. La ironía de la liberación sexual es acaso que el autocontrol, que se promovía desde las proclamas a favor de la reapropiación del cuerpo de las mujeres, ha generado inauditas esclavitudes que las mujeres han de aceptar o aceptan tout court para ser dueñas de su identidad.

El feminismo igualitarista soñaba con una mujer esencialmente liberada de la feminidad. Desde el moderadamente candoroso desideratum de una «mujer varonil» por parte de Mary Wollstonecraf hasta la feroz e hiperbólica diatriba contra la figura de la "pondeuse», en $E l$ segundo sexo, la perspectiva de la igualdad ha tratado de abstraer de las mujeres todo aquello que las hace vulnerables a algún tipo de equívoco que dé pie a excluirlas de la cobertura de un concepto de «Ser Humano Autónomo». Esta pretensión igualitarista parecería perder

7. En 1970 el Boston Women's Health Book Collective saca a la luz un volumen con el título Women and Their Bodies (Boston, Massachusetts, 1970). La $1^{\text {a }}$ edición con el título Our Bodies Ourselves data de 1973.

8. Ver el último libro de Putnam, Hillary: The Collapse of the Fact/Value Dichotomy, Cambridge Massachusetts, Harvard University Press, 2002. 
parte de su carácter abstracto cuando se piensa en una igualdad que pasa por la reapropiación de la identidad que exige prioritariamente la ruptura con el estatuto previo de objeto sexual. Sin embargo, en realidad, esta reapropiación de la identidad como sujeto se basa en un proceso de borradura de todo aquello que, por su carácter no unívoco, permitiría transitar entre el estatuto de la mujer como sujeto y su estatuto como objeto. No cabe duda de que, en el territorio de una identidad sexual, y también en otros, el igualitarismo no ha logrado imponer sus pretensiones de una cierta androginia. Pero sería demasiado ingenuo concluir de ello que, merced a la reacción diferencialista, se han exacerbado aquellos rasgos de lo femenino que el igualitarismo trataba de desdibujar, y se ha producido esta ambigüedad, cuando no regresión, en la manifestaciones e interpretaciones de las imágenes femeninas, que hoy constituyen la presentación dominante en los media, y la base de una ideología que pone en tela de juicio la oposición feminista a la objetualización del cuerpo femenino.

Si hay un cambio radical entre la objetualización tradicional de las mujeres y la actual situación que califico de ambigua, cambio al que sin duda el feminismo ha contribuido acentuadamente, es precisamente el olvido de la violencia patriarcal que hacía de las mujeres objetos sexuales, y la transformación de la resistencia, o la indignación, en una satisfecha apropiación de una imagen sexual que hubiera resultado intolerable desde una perspectiva feminista hace algunos decenios. ¿Cómo podemos tratar de explicar este cambio?

Si las mujeres sólo han sido aceptables, y esto en todos los sentidos del término, muy especialmente en el sentido moral, tras ser ahormadas, formalizadas según el molde de la feminidad que las hace sencillamente "posibles", tal violencia normativa no ha dejado de ser eficiente. La creciente sospecha que una revisión crítica del feminismo nos podría llevar a albergar es que justamente al permitirse a las mujeres establecer su estatuto de sujetos se las ha convertido en cómplices de su propia autoidealización.

Las mujeres han heredado una metafísica del sujeto que sólo permite pensarlo, y pensarse por ello, en términos de unidad, de conformidad, de armonía interior ${ }^{9}$-y esto atañe tanto a la más clara y más prolijamente discutida versión del igualitarismo como a la quizá menos obvia del diferencialismo ${ }^{10}$.

El feminismo $-y$, si bien me consta que es inexacto referirse a ello de este modo, a efectos de mi argumento este singular es apropiado- ha asumido, no sin cierto candor, que poseer una identidad como sujetos significa para las mujeres un estado de conformidad y de armonía "consigo mismas». Aunque lograr ese estado de armonía pudiera ser equivalente a liberarse de las imposiciones patriarcales, el hecho es que el imperativo de la autocomplacencia, al menos en el estado actual de cosas, es un arma de doble filo, que sin duda puede llevar, y

9. En el texto inédito "La genealogía del mal» hago explícito de manera más clara en qué consiste exactamente esta necesidad de conformidad interna.

10. En el trabajo inédito "Dos dogmas del Feminismo» analizo más pormenorizadamente esta no evidente semejanza. 
de hecho lo hace, a las mujeres a aceptar la misma imposición normativa de la que antes se consideraban víctimas; sólo que en esta ocasión de buen grado.

Tanto desde el punto de vista ético como desde el punto de vista estético, las mujeres han sido ordenadas, unificadas, ahormadas, formalizadas para evitar el mal que en su estado natural comportan su delicuescencia corporal, y su carácter mudadizo son las dos caras de una misma moneda. La falta de unidad interior es síntoma del mal, y en cierto modo, por ello, de falta de identidad ${ }^{11}$.

No cabe duda de que es posible pensar en una identidad aun conformada sobre la idea de la armonía y la unidad interna que se separe del canon platonizante al que me he referido hasta ahora. No obstante, el resultado de esa necesidad tradicional de pensar el sujeto exclusivamente como una unidad interna, creo, es responsable de al menos parte de las ambigüedades con que las mujeres se presentan o autopresentan y se interpretan o autointerpretan. La necesidad de unificar el yo para convertirse en dueñas de una identidad propia obliga a las mujeres a establecer una estrategia constructiva que las convierte en seres plásticos, "formalizados» según el estándar público que ellas acogen con gusto, o, en su defecto, a convertir su imagen en un espejismo de sus buenos deseos. En cualquiera de los dos casos, se trata de evitar la angustia de un desgarro prohibido -prohibido metafísicamente. En resumidas cuentas, la mujer que había de ser aceptada a toda costa por el varón para adquirir algún estatuto social, ha pasado a tener que autoaceptarse en términos semejantes, que implican el mismo tipo de maniobras metafísicas, para adquirir identidad. Si un proceso implicaba una importante pérdida, no es menor la pérdida en el otro. La caricatura de quien invierte su energía, su salud y su dinero en someterse a cruentos procesos de rejuvenecimiento, o de quien, en el envés de la misma historia, trata de hacer explícita la belleza de lo feo, dista muy poco de la imagen idealizada de una mujer cuyo cuerpo adquiere la dureza del mármol o la inocencia de una diosa guerrera. En todos los casos se trata de hacer invisible e implausible la contingencia y la incertidumbre. Cosas ambas que, según nuestra tradición metafísica, parecen poner en tela de juicio la identidad de cualquier sujeto.

11. Remito al lector a la discusión aristotélica acerca del desgarro interior que es propiedad de los malos en la Ética a Nicómaco, Libros VIII y IX. Mi trabajo "Genealogía del mal» es una reflexión acerca de esto mismo. 